\title{
L-Histidine Augments the Response to 1-Deamino-8-D-Arginine Vasopressin in Brattleboro Homozygous (di/di) Rats
}

\author{
Gerald Charnogursky, Arnold M. Moses, Richard Coulson, Marc Bernstein, and Christos P. Carvounis \\ Sections of Endocrinology and Nephrology, Department of Medicine, and Department of Pharmacology, Veterans Administration \\ Medical Center, and State University of New York Health Science Center, Syracuse, New York 13210
}

\begin{abstract}
Studies in vitro have shown that L-histidine increases the hydroosmotic response to vasopressin. We examined whether this phenomenon occurs also in vivo. Homozygous Brattleboro rats (di/di) were fed a regular diet $(0.5 \%$ histidine) or a diet enriched with histidine and received $1 \mathrm{ng}$ of 1-deamino-8-D-arginine vasopressin (dDAVP) daily. Addition of histidine (1\% by weight) increased post-dDAVP urine osmolality to a level higher than that of control (502 $\pm 62 \mathrm{vs.} 316 \pm 36 \mathrm{mosmol} / \mathrm{kg}, P$ $<0.05$ ). Similar results were seen with $3.0 \%$ and $5.5 \%$ dietary histidine. There were significant increases in free-water reabsorption and in the ratio of free-water reabsorption to osmolar clearance, but no difference in osmolal clearance. No signifcant effect was found with supplemental histidine of $0.5 \%$ or less. The cause for these findings appears not to be the metabolism of histidine, since the nonmetabolizable D-histidine had a significant, albeit smaller, effect, and the isonitrogenous addition of albumin, alanine, arginine, or glutamine was ineffective. In part, histidine may operate by increasing CAMP since the renal cAMP content in response to vasopressin is increased in histidine-fed rats $(13.1 \pm 0.9$ vs. $9.8 \pm 0.8 \mathrm{nmol} / \mathrm{g}$ dry weight, $P$ $<0.01$ ). The role of prostaglandins appears less clear. Histidine greatly decreased urinary $\mathrm{PGE}_{2}$ during baseline (1.5 \pm 0.3 vs. $7.0 \pm 2.3 \mu \mathrm{g} / \mathrm{mg}$ creatinine, $P<0.001$ ), but it profoundly augmented urinary prostaglandin excretion after dDAVP stimulation (40.0 \pm 4.2 vs. $7.0 \pm 2.0 \mu \mathrm{g} / \mathrm{mg}$ creatinine, $P<0.001)$. (J. Clin. Invest. 1990. 85:921-928.) cyclic AMP • histidine • prostaglandins • vasopressin
\end{abstract}

\section{Introduction}

Our understanding of the role of naturally occurring amino acids in biological systems is continually increasing. Various amino acids affect membrane permeability $(1,2)$, cyclic AMP (cAMP) production $(3,4)$, cellular electrolyte composition $(1,2,5,6)$, cellular osmoregulation (7), and heavy-metal chelation (8).

Parts of this work have been presented to the 43rd Annual Meeting of the American Federation for Clinical Research, Washington, DC, 1986, and the 13th International Congress of Nephrology, London, England, 1987

Address reprint requests to Dr. Carvounis, Division of Nephrology, Nassau County Medical Center, 2201 Hempstead Turnpike, East Meadow, NY 11554

Received for publication 5 June 1987 and in revised form 30 October 1989.

The Journal of Clinical Investigation, Inc.

Volume 85, March 1990, 921-928
Several amino acids are known to alter vasopressin-stimulated water flow in the toad bladder (9). Vasopressin-stimulated water flow is increased by L-histidine, L-glutamate, and L-lysine and decreased by L-glutamine. L-Histidine has the greatest augmenting effect, increasing the vasopressin-stimulated water flow by $75 \%$ over control. This effect of $L$-histidine was postulated to be mediated by a physiochemical property of its imidazole ring, such as chelation of zinc intracellularly. This would then allow formation of microtubules which are important in the action of vasopressin (9).

In this article, we show that dietary supplements of L-histidine (1.0-5.0\% by weight) augment the urinary concentrating response to injected 1-deamino-8-D-arginine vasopressin (dDAVP $)^{1}$ in female homozygous Brattleboro rats. This in vivo response in the mammal is analogous to the response in the toad bladder. The augmenting effect of L-histidine occurs without changes in osmolar clearance or creatinine excretion and is not related to inhibition of prostaglandin synthesis.

\section{Methods}

Adult female Brattleboro rats, homozygous for diabetes insipidus, were used in all experiments. Three 1-wk test periods were employed (Fig. 1). During periods $A$ and $C$ rats received standard powdered laboratory diets (R-M-H 3000 certified rodent diet, $22 \%$ protein including $0.51 \%$ histidine, Charles River Breeding Laboratories, Inc., Wilmington, MA). During period B, the standard diet was supplemented with varied concentrations of L-histidine $(0.05-5.0 \%)$ for a total dietary histidine content ranging from $0.56 \%$ to $5.51 \%$ by weight. Since the histidine contained in the regular laboratory diet is within the range of the normal histidine requirement for rats (10), it follows that the present study deals with effects of supplemental histidine in normally fed rats rather than supplementation of histidine in histidine-depleted rats. There was no significant difference in weight gain of rats fed these various diets.

During the final $2 \mathrm{~d}$ of each test period, each rat received subcutaneously $1 \mathrm{ng}$ of dDAVP in $0.1 \mathrm{ml}$ of sterile water. 6-h urine specimens were collected for volume, osmolality, creatinine, sodium, and potassium. The combined 2-d 6-h collections are used throughout this study to represent the antidiuretic phase. During the $2 \mathrm{~d}$ immediately preceding the dDAVP injection, similar 6-h specimens were collected. These represent the water diuresis phase, since in the Brattleboro rat, the absence of vasopressin production results in water diuresis. Separate rats were used for each group of experiments.

At the end of each collection period, urine volume and osmolality were determined before freezing the specimens for subsequent analyses. Osmolality was determined by freezing point depression on an osmometer (Digi-Matic, Advanced Instruments, Inc., Needham Heights, MA). Urine creatinine was determined by Auto Analyzer. Serum creatinines were determined by a microassay technique (11). Serum and urine sodium and potassium concentrations were deter-

1. Abbreviation used in this paper: dDAVP, 1-deamino-8-D-arginine vasopressin. 


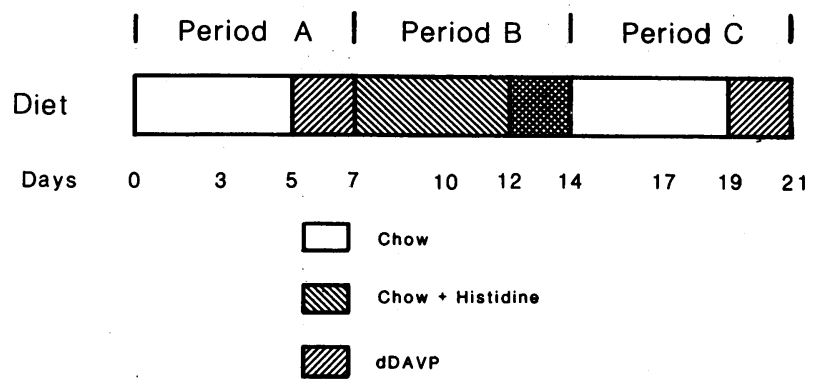

Figure 1. Schematic representation of the diet and the antidiuretic status of the rats used in the present studies. Rats were fed regular chow during period A. Histidine was added to their diet in period B, and regular chow was fed again during period $C$. Each period lasted $1 \mathrm{wk}$. dDAVP was injected in the mornings of the last $2 \mathrm{~d}$ of each period. Blood and urine collections during the $2 \mathrm{~d}$ preceding dDAVP infusion represent the water diuresis phase. The $2 \mathrm{~d}$ that dDAVP was injected represent the antidiuretic phase.

mined by flame photometer. Urines for $\mathrm{PGE}_{2}$ determinations were collected in cups containing sodium azide and mefenamic acid so as to inhibit $\mathrm{PGE}_{2}$ breakdown and production. Urinary $\mathrm{PGE}_{2}$ was determined by radioimmunoassay using tritiated $\mathrm{PGE}_{2}$ (Amersham Corp., Arlington Heights, IL) by the method of Moses et al. (12). Intra-assay percent error for $\mathrm{PGE}_{2}$ was $6.16 \%$ and interassay percent error was $7.09 \%$.
In a separate set of experiments we evaluated the effects of dietary histidine on cAMP content of kidneys of Brattleboro rats fed either control chow or chow $+5 \%$ histidine for 1 wk before perfusion (13). Kidneys were perfused in Krebs-Henseleit bicarbonate Ringer's buffer at a constant pressure $(100 \mathrm{~mm} \mathrm{Hg})$ for $60 \mathrm{~min}$. In some of the experiments dDAVP $(0.4 \mathrm{nM})$ was added to the perfusate (13). After perfusion the kidneys were frozen immediately by freeze-clamping. cAMP was measured by radioimmunoassay. In another set of experiments we determined the cortical and medullary tonicity of the kidneys of rats fed either normal laboratory diet, that plus $1 \%$ histidine, or normal laboratory diet plus $5 \%$ histidine for $10 \mathrm{~d}$. The kidneys were removed and the cortex and medulla were separated and weighed $(14,15)$, After homogenization in $10 \mathrm{ml}$ of distilled water, samples were removed immediately for colorimetric determination of urea and ammonium (16). The remaining homogenate was then heated at $100^{\circ} \mathrm{C}$ for $1 \mathrm{~h}$, cooled, and centrifuged, and the supernatant fluid was analyzed for sodium and potassium by flame photometry $(14,15)$. The water content was extrapolated from the wet and dry weight of tissues determined before and after dessication at $95^{\circ} \mathrm{C}$ for $48 \mathrm{~h}$. "Total solute" concentration in tissue was calculated from $2\left(\mathrm{Na}^{+}+\mathrm{K}^{+}+\mathrm{NH}^{+}\right)$ + urea. In some tissues the osmolality of the homogenate was determined directly and tissue osmolality was extrapolated. Plasma histidine was determined by Dr. Anil Palekar using an amino acid analyzer (Beckman Instruments, Inc., Fullerton, CA). dDAVP in sterile aqueous solution was purchased from USV Pharmaceutical Corp., Tarrytown, NY. L-histidine, D-histidine, L-glutamine, L-arginine, L-alanine, and albumin were purchased from the Sigma Chemical Co., St. Louis, MO. Statistical analysis was performed by using Student's paired $t$ test. For cAMP determinations in unpaired tissue we used the

Table I. Antidiuresis

\begin{tabular}{|c|c|c|c|c|c|c|}
\hline & $n$ & $\mathbf{v}$ & Uosm & Cosm & $T_{C_{1000}}$ & $\mathrm{~T}_{\mathrm{C}_{\mathrm{mod}} / \operatorname{Cosm}}$ \\
\hline & & $\mu l / m i n$ & mosmol/kg & $\mu l / m i n$ & $\mu l / m i n$ & $\%$ \\
\hline Control & 10 & $14.4 \pm 5.4$ & $389.1 \pm 42.6$ & $14.7 \pm 3.2$ & $0.3 \pm 2.4$ & $14.5 \pm 9.5$ \\
\hline Control & & $11.8 \pm 2.9$ & $418.1 \pm 29.2$ & $14.3 \pm 2.7$ & $2.5 \pm 0.5$ & $24.6 \pm 5.2$ \\
\hline$P$ & & NS & NS & NS & NS & NS \\
\hline Control & 6 & $17.6 \pm 3.8$ & $344.4 \pm 38.3$ & $17.5 \pm 3.3$ & $-0.15 \pm 1.2$ & $3.3 \pm 9.7$ \\
\hline $0.05 \%$ & & $15.6 \pm 2.9$ & $370.0 \pm 40.2$ & $16.8 \pm 1.7$ & $1.2 \pm 1.5$ & $11.3 \pm 10.3$ \\
\hline$P$ & . & NS & NS & NS & NS & NS \\
\hline Control & 8 & $8.8 \pm 1.9$ & $420.3 \pm 39.1$ & $10.8 \pm 1.7$ & $2.0 \pm 0.7$ & $23.3 \pm 6.5$ \\
\hline $0.1 \%$ & & $12.2 \pm 2.5$ & $411.1 \pm 29.2$ & $15.3 \pm 2.4$ & $3.1 \pm 0.6$ & $23.6 \pm 4.8$ \\
\hline$P$ & & NS & NS & NS & $<0.05$ & NS \\
\hline Control & 6 & $16.7 \pm 4.4$ & $362.1 \pm 37.2$ & $16.8 \pm 3.6$ & $0.1 \pm 1.7$ & $8.8 \pm 9.3$ \\
\hline $0.5 \%$ & & $13.2 \pm 2.1$ & $449.2 \pm 49.3$ & $17.5 \pm 1.9$ & $4.2 \pm 1.3$ & $26.0 \pm 7.5$ \\
\hline$P$ & & NS & NS & NS & NS & NS \\
\hline Control & 6 & $14.2 \pm 3.1$ & $313.5 \pm 35.9$ & $12.6 \pm 2.4$ & $-1.5 \pm 2.1$ & $-9.4 \pm 5.1$ \\
\hline $1 \%$ & & $10.0 \pm 9.6$ & $502.1 \pm 62.6$ & $14.7 \pm 2.6$ & $4.8 \pm 1.8$ & $33.2 \pm 8.1$ \\
\hline$P$ & & NS & $<0,05$ & NS & $<0.05$ & $<0.05$ \\
\hline Control & 8 & $14.4 \pm 2.8$ & $319.2 \pm 24.6$ & $14.1 \pm 2.6$ & $-0.4 \pm 0.9$ & $0.3 \pm 7.7$ \\
\hline $2.5 \%$ & & $9.0 \pm 1.8$ & $515.6 \pm 25.1$ & $14.3 \pm 2.4$ & $5.3 \pm 0.7$ & $40.1 \pm 3.3$ \\
\hline$P$ & & $<0.01$ & $<0.001$ & NS & $<0.001$ & $<0.001$ \\
\hline Control & 16 & $13.2 \pm 1.5$ & $376.5 \pm 20.3$ & $15.1 \pm 1.3$ & $2.0 \pm 0.9$ & $14.5 \pm 6.0$ \\
\hline $5 \%$ & & $10.9 \pm 2.2$ & $503.1 \pm 29.8$ & $15.5 \pm 2.1$ & $4.7 \pm 0.8$ & $35.5 \pm 4.6$ \\
\hline$P$ & & NS & $<0.001$ & NS & $<0.001$ & $<0.001$ \\
\hline Control & 6 & $10.4 \pm 1.9$ & $310.0 \pm 40.0$ & $10.8 \pm 4.2$ & $1.3 \pm 1.8$ & $-2.5 \pm 12.7$ \\
\hline $8.5 \%$ & & $13.5 \pm 2.8$ & $450.0 \pm 49.1$ & $18.7 \pm 2.7$ & $5.2 \pm 0.5$ & $30.5 \pm 6.8$ \\
\hline$P$ & & NS & $<0.05$ & $<0.05$ & $<0.05$ & $<0.05$ \\
\hline
\end{tabular}

The effects of variable histidine intake on renal concentrating ability are shown. Antidiuresis was produced by 1 injection of ng of dDAVP. Statistical analysis was performed using paired Student's $t$ tests; NS, no significant change. The concentration of histidine noted in this and subsequent tables represents percent histidine by weight added to the regular laboratory diet that contains $0.51 \%$ histidine. Abbreviations: $\mathrm{V}$, volume; Uosm, urine osmolality, Cosm, osmolar clearance, $\mathrm{T}_{\mathrm{C}_{\mathrm{H}, \mathrm{O}}}$ free-water reabsorption. 
nonpaired analysis. Results are expressed as mean \pm standard error of mean (SEM).

\section{Results}

Effects of histidine during antidiuresis (Table I). In five rats fed $5 \%$ histidine supplementation, the baseline osmolality increased in response to dDAVP to values almost twice as high as those during the control periods (Fig. 2). The urine volume diminished during the histidine supplementation and rose again to its pre-histidine values while back on the standard diet $(P<0.05)$. Since reversibility was demonstrated, subsequent experiments did not involve a second control period.

dDAVP resulted in significant differences in urine volume and osmolality compared with those of the control period in the rats fed L-histidine in amounts of $1 \%$ or greater (Fig. 3), but not for rats fed $<0.5 \%$ (Fig. 4). No significant difference in osmolar clearance or creatinine excretion was noted except for the animals on the $8.5 \%$ diet.

Volume was decreased by an average of $\sim 30 \%$ in all experiments in which rats were fed $0.5 \%$ or more histidine. This difference did not reach significance in every category, reflecting the variability encountered. However, statistical signifcance was found for the rats fed $2.5 \%$ histidine (see Table II) and the subset fed 5\% histidine (Fig. 2). Differences were statistically significant for each group if the first day was considered separately, and for all rats fed $1 \%, 2.5 \%$, and $5 \%$ histidine, if pooled together (Fig. 3).

Endogenous creatinine clearances were measured in 15 rats. These were performed at the end of period $A$ and at the end of period B. A trend towards increased creatinine clearance with time was noted at the end of period B (compared to the end of period $A)$, in both the control $(1,268 \pm 423$ vs. $1,053 \pm 302 \mu \mathrm{l} / \mathrm{min})$ and the histidine-treated rats $(1,385 \pm 81$ vs. $997 \pm 175 \mu \mathrm{l} / \mathrm{min})$. The increase in the histidine treated

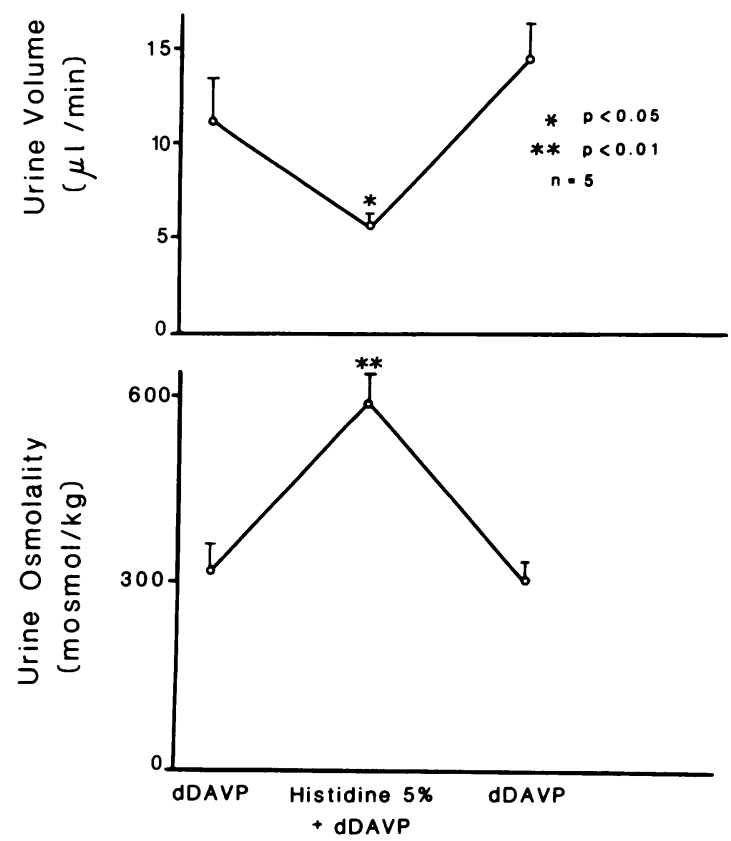

Figure 2. Schematic representation of the effect of addition of 5\% histidine to regular rat chow diet on the urine volume and osmolality response to $\mathrm{dDAVP}$ during periods $\mathrm{A}, \mathrm{B}$, and $\mathrm{C}$.

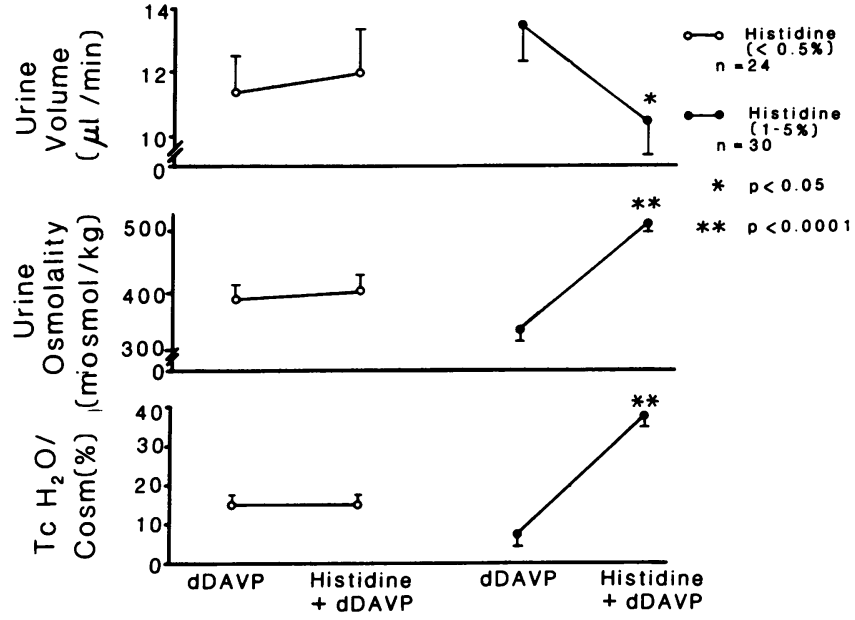

Figure 3. The effects of low doses of histidine (0-0.5\%) are compared with those of high dietary histidine (1-5\%). (0) Low-dose histidine; (•) high-dose histidine. High doses of histidine have a profound effect on the concentrating ability. This is quite different from the lack of effectiveness shown for the low-dose histidine group. Note that histidine concentration in this and subsequent figures represent percent histidine by weight added to the regular laboratory diet that contained $0.51 \%$ histidine.

group was larger ( $40 \%$ increase vs. $20 \%$ ) and also reached statistical significance $(P<0.05)$. However, there was no significant difference in serum creatinines or creatinine clearance in any of these periods between control and histidine treated rats.

Effects of histidine during water diuresis (Table II). In the absence of dDAVP there was no significant change in urine volume or urinary osmolality in response to supplementation with L-histidine in concentrations of $0.05 \%$ or less. At higher concentrations there was a fall in urine volume and a rise in urine osmolality.

There was no significant change in osmolar clearance, free-water clearance, and the ratio of free-water clearance to volume in control vs. $0.05,2.5 \%$ L-histidine supplements. Ad-
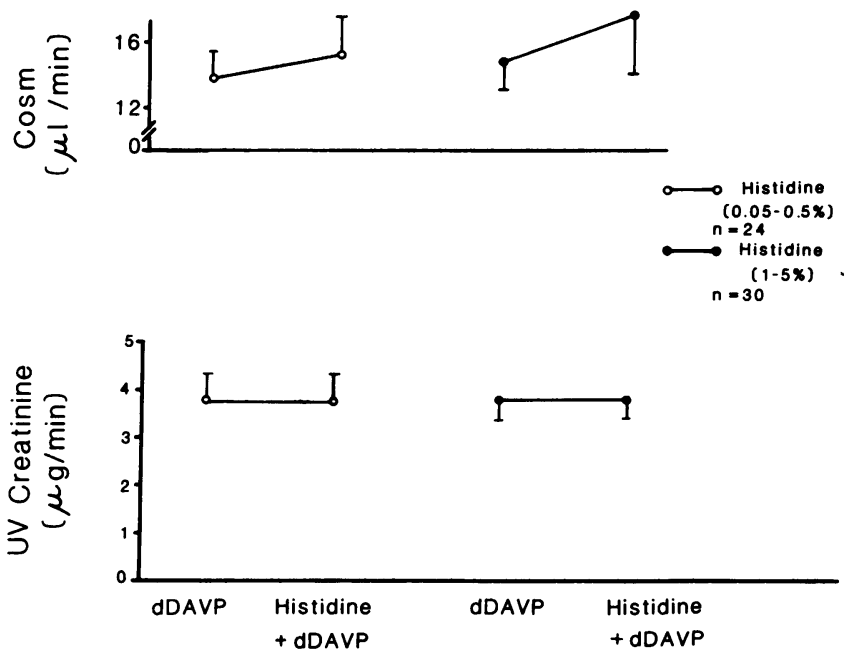

Figure 4. Feeding histidine at either a low (O) or high $(\bullet)$ concentration had no effect on osmolar clearance or on urinary creatinine. As indicated in the text, creatinine clearance was also not affected. 


\begin{tabular}{|c|c|c|c|c|c|c|}
\hline & $n$ & $\mathbf{v}$ & Uosm & Cosm & $\mathrm{C}_{\mathrm{H}_{2} \mathrm{O}}$ & $\mathrm{C}_{\mathrm{H}_{2} \mathrm{O}} / \mathrm{V}$ \\
\hline & & $\mu l / m i n$ & $\mathrm{mosmol} / \mathrm{kg}$ & $\mu l / \min$ & $\mu l / m i n$ & $\%$ \\
\hline Control & 10 & $56.0 \pm 5.7$ & $126.1 \pm 8.4$ & $23.0 \pm 2.0$ & $33.0 \pm 4.3$ & $58.0 \pm 2.8$ \\
\hline Control & & $61.0 \pm 6.0$ & $128.8 \pm 7.3$ & $25.5 \pm 2.2$ & $35.5 \pm 4.3$ & $57.1 \pm 2.4$ \\
\hline$P$ & & NS & NS & NS & NS & NS \\
\hline Control & 6 & $69.3 \pm 4.4$ & $128.3 \pm 10.9$ & $32.8 \pm 2.1$ & $36.5 \pm 4.1$ & $60.6 \pm 3.6$ \\
\hline $0.05 \%$ & & $66.4 \pm 6.7$ & $136.5 \pm 16.8$ & $28.2 \pm 2.1$ & $38.2 \pm 5.8$ & $54.5 \pm 5.6$ \\
\hline$P$ & & NS & NS & NS & NS & NS \\
\hline Control & 8 & $48.8 \pm 4.6$ & $125.1 \pm 6.7$ & $19.6 \pm 1.1$ & $29.2 \pm 3.7$ & $58.3 \pm 2.2$ \\
\hline $0.1 \%$ & & $56.4 \pm 5.6$ & $137.7 \pm 9.3$ & $25.0 \pm 1.8$ & $31.3 \pm 4.1$ & $54.1 \pm 3.1$ \\
\hline$P$ & & NS & NS & $<0.01$ & NS & NS \\
\hline Control & 6 & $57.1 \pm 6.1$ & $126.2 \pm 7.4$ & $23.5 \pm 2.3$ & $33.6 \pm 4.5$ & $58.0 \pm 2.5$ \\
\hline $0.5 \%$ & & $59.7 \pm 6.5$ & $140.2 \pm 10.8$ & $26.4 \pm 1.7$ & $33.3 \pm 5.2$ & $53.3 \pm 3.6$ \\
\hline$P$ & & NS & NS & NS & NS & NS \\
\hline Control & 6 & $63.9 \pm 6.5$ & $126.5 \pm 7.1$ & $26.6 \pm 1.9$ & $36.9 \pm 4.7$ & $57.9 \pm 2.3$ \\
\hline $1 \%$ & & $63.3 \pm 5.9$ & $138.7 \pm 10.6$ & $26.0 \pm 1.6$ & $37.3 \pm 7.6$ & $53.8 \pm 6.6$ \\
\hline$P$ & & NS & NS & NS & NS & NS \\
\hline Control & 8 & $67.6 \pm 1.7$ & $128.8 \pm 11.6$ & $24.4 \pm 1.9$ & $43.2 \pm 2.9$ & $57.1 \pm 3.9$ \\
\hline $2.5 \%$ & & $61.2 \pm 8.8$ & $134.2 \pm 6.3$ & $26.8 \pm 3.7$ & $34.4 \pm 6.1$ & $55.3 \pm 1.8$ \\
\hline$P$ & & NS & NS & NS & NS & NS \\
\hline Control & 16 & $68.0 \pm 3.9$ & $123.9 \pm 4.4$ & $27.8 \pm 1.6$ & $40.2 \pm 2.8$ & $58.7 \pm 1.5$ \\
\hline $5 \%$ & & $59.4 \pm 4.9$ & $144.8 \pm 10.6$ & $27.6 \pm 2.3$ & $31.8 \pm 3.4$ & $51.8 \pm 3.5$ \\
\hline$P$ & & $<0.01$ & $<0.01$ & NS & $<0.001$ & $<0.01$ \\
\hline Control & 6 & $71.2 \pm 5.3$ & $103.0 \pm 8.6$ & $24.9 \pm 2.6$ & $46.3 \pm 4.9$ & $65.6 \pm 2.9$ \\
\hline $8.5 \%$ & & $59.4 \pm 6.4$ & $155.0 \pm 16.0$ & $28.9 \pm 2.3$ & $30.5 \pm 6.3$ & $48.5 \pm 5.3$ \\
\hline$P$ & & $<0.02$ & $<0.05$ & $<0.01$ & $<0.01$ & $<0.05$ \\
\hline
\end{tabular}

The effects of variable histidine intake on baseline water excretion are shown. Every group has a control period (receiving $0 \%$ histidine) and an experimental period (receiving variable amounts of histidine). Statistics and abbreviations similar to those in Table I: $\mathrm{C}_{\mathrm{H}_{2} \mathrm{O}}$, free-water clearance.

dition of $5 \%$ histidine significantly reduced the free-water clearance $(40.2 \pm 31.8$ vs. $2.8 \pm 3.4 \mu \mathrm{l} / \mathrm{ml}, P<0.001)$, and the ratio of free-water clearance to volume $(58.7 \pm 51.8 \mathrm{vs}$. $10.5 \pm 3.5 \mu \mathrm{l} / \mathrm{ml}, P<0.01)$ but had no effect on osmolar clearance. In contrast, $8.5 \% \mathrm{~L}$-histidine led to a significant increase in the osmolar clearance $(28.9 \pm 2.3$ vs. $24.9 \pm 2.6 \mu \mathrm{l} / \mathrm{min}, P$ $<0.01)$ and this dose was not used in subsequent experiments.

Specificity of histidine effect (Table III). To evaluate whether the increased antidiuresis found with histidine may reflect its nitrogen content and metabolism (urea generation) (17), we evaluated a series of rats fed isonitrogenous supplements of $2 \%$ albumin, $1 \%$ L-glutamine, $1 \%$ L-arginine, $2 \%$ L-alanine, or $1 \%$ D-histidine (Table III). The nonmetabolizable D-histidine qualitatively reproduced the effects seen with Lhistidine. In response to dDAVP, urine volume and osmolality were no different in the presence of any of the remaining compounds.

cAMP content (Fig. 5). cAMP content of kidneys perfused in vitro in the absence of dDAVP was similar in both the histidine fed and control rats. In the control rats, dDAVP increased the cAMP content to $9.82 \pm 0.80 \mathrm{nmol} / \mathrm{g}$ dry weight. Feeding with histidine resulted in a greater increase in tissue cAMP after dDAVP was added (13.12 $\pm 0.86 \mathrm{nmol} / \mathrm{g}$ dry weight, $P<0.001$ ).

$P G E_{2}$ (Figs. 6-8). $\mathrm{PGE}_{2}$ excretion was assessed rats on supplemental $1 \%, 2.5 \%$, and $5 \%$ histidine. In the absence of dDAVP, there was a clear fall in urinary $\mathrm{PGE}_{2}$ excretion (from $7.0 \pm 2.3$ to $1.5 \pm 0.3 \mathrm{ng} / \mathrm{mg}$ creatinine, $P<0.001$ ) at all histi- dine doses (Figs. 6 and 8). In contrast, histidine increased $\mathrm{PGE}_{2}$ excretion in the presence of dDAVP (from 7.0 \pm 2.0 to $40 \pm 4.2 \mathrm{ng} / \mathrm{mg}$ creatinine, $P<0.0001$ ) (Figs. 7 and 8 ).

Medullary tonicity (Table IV). In these experiments cortical and medullary tonicity was assessed. As a measure of tissue tonicity, we used the content of electrolytes $\left(\mathrm{Na}^{+}+\mathrm{K}^{+}\right.$ $+\mathrm{NH}^{+}$), and nonelectrolytes (urea) as reported previously $(14,15)$. Rats fed for $10 \mathrm{~d}$ with diets containing $1 \%$ or $5 \%$ histidine had no significant changes in medullary tonicity, compared with their control-fed counterparts. In some rats, medullary tonicity was measured directly. There too, no significant differences were shown between control $(715 \pm 51), 1 \%$ histidine $(722 \pm 121)$, and $5 \%$ histidine $(747 \pm 162)$.

Effects of histidine on $\mathrm{Na}^{+}$and $\mathrm{K}^{+}$excretion (Table $\mathrm{V}$ ). Addition of histidine to the diet decreases natriuresis during the water diuresis phase. No substantial changes were found during antidiuresis.

Effects of histidine on plasma histidine concentration. Addition of histidine to the diet increased plasma histidine from $29 \pm 2 \mathrm{mM}, n=5$ (control diet) to $35 \pm 3, n=5$ (1\% histidine) to $47 \pm 4, n=5$ ( $5 \%$ histidine)

\section{Discussion}

L-Histidine enhanced the urinary concentrating response to exogenous dDAVP in the homozygous Brattleboro rat. This effect occurred in the absence of significant changes in solute or creatinine excretion and was not related to inhibition of 


\begin{tabular}{|c|c|c|c|c|c|c|}
\hline & \multicolumn{6}{|c|}{ Water diuresis } \\
\hline & $n$ & $\mathbf{v}$ & Uosm & Cosm & $\mathrm{C}_{\mathrm{H}_{2} \mathrm{O}}$ & $\mathrm{C}_{\mathrm{H}_{2} \mathrm{O}} / \mathrm{V}$ \\
\hline & & $\mu l / m i n$ & $\mathrm{mosmol} / \mathrm{kg}$ & $\mu \mathrm{l} / \mathrm{min}$ & $\mu l / m i n$ & $\%$ \\
\hline Control & 6 & $77.5 \pm 5.3$ & $113 \pm 7$ & $28.4 \pm 1.2$ & $49.0 \pm 4.4$ & $62.4 \pm 2.3$ \\
\hline Albumin, $2 \%$ & & $63.3 \pm 6.7$ & $129 \pm 6$ & $26.8 \pm 2.6$ & $36.6 \pm 4.6$ & $57.1 \pm 1.8$ \\
\hline$P$ & & $<0.02$ & $<0.02$ & NS & $<0.001$ & $<0.02$ \\
\hline Control & 4 & $93.3 \pm 12.8$ & $106 \pm 7$ & $31.8 \pm 2.6$ & $61.4 \pm 10.4$ & $64.7 \pm 2.3$ \\
\hline Glutamine, $1 \%$ & & $75.8 \pm 8.9$ & $116 \pm 7$ & $28.4 \pm 2.4$ & $47.4 \pm 6.8$ & $61.5 \pm 2.5$ \\
\hline$P$ & & NS & NS & NS & NS & NS \\
\hline Control & 4 & $82.3 \pm 16.1$ & $119 \pm 21$ & $35.2 \pm 4.8$ & $62.2 \pm 15.6$ & $43.6 \pm 4.9$ \\
\hline Arginine, $1 \%$ & & $97.6 \pm 16.9$ & $156 \pm 37$ & $36.1 \pm 5.6$ & $46.2 \pm 16.3$ & $34.6 \pm 8.8$ \\
\hline$P$ & & NS & NS & NS & NS & NS \\
\hline Control & 4 & $107.3 \pm 14.5$ & $120 \pm 14$ & $41.1 \pm 3.4$ & $66.2 \pm 13.1$ & $43.1 \pm 3.4$ \\
\hline Alanine, $2 \%$ & & $119.8 \pm 22.0$ & $96 \pm 16$ & $35.8 \pm 6.8$ & $84.0 \pm 18.1$ & $49.1 \pm 3.9$ \\
\hline$P$ & & NS & NS & NS & NS & NS \\
\hline Control & 9 & $78.4 \pm 7.8$ & $104 \pm 7$ & $26.3 \pm 2.3$ & $52.1 \pm 5.9$ & $47.1 \pm 1.7$ \\
\hline D-Histidine, $1 \%$ & & $56.0 \pm 2.0$ & $113 \pm 9$ & $21.0 \pm 1.7$ & $35.0 \pm 2.4$ & $44.7 \pm 2.2$ \\
\hline \multirow[t]{4}{*}{$P$} & & $<0.02$ & $<0.02$ & NS & $<0.01$ & NS \\
\hline & \multicolumn{6}{|c|}{ Antidiuresis } \\
\hline & $n$ & $\mathbf{v}$ & Uosm & Cosm & $T_{\mathrm{C}_{\text {noO }}}$ & $T_{\mathrm{CH}_{\mathrm{mod}} / \operatorname{Cosm}}$ \\
\hline & & $\mu l / \min$ & $\mathrm{mosmol} / \mathrm{kg}$ & $\mu l / \min$ & $\mu l / m i n$ & $\%$ \\
\hline Control & 6 & $22.2 \pm 2.6$ & $279 \pm 15$ & $19.5 \pm 1.5$ & $-2.7 \pm 1.5$ & $-11.3 \pm 6.5$ \\
\hline Albumin, $2 \%$ & & $28.5 \pm 6.7$ & $265 \pm 27$ & $22.2 \pm 3.4$ & $-6.3 \pm 4.4$ & $-23.0 \pm 14.9$ \\
\hline$P$ & & NS & NS & NS & NS & NS \\
\hline Control & 4 & $13.6 \pm 3.3$ & $294 \pm 23$ & $12.3 \pm 2.5$ & $-1.3 \pm 0.8$ & $-5.5 \pm 7.0$ \\
\hline Glutamine, $1 \%$ & & $17.2 \pm 6.5$ & $293 \pm 30$ & $15.8 \pm 2.8$ & $-1.4 \pm 4.6$ & $-6.4 \pm 15.8$ \\
\hline$P$ & & NS & NS & NS & NS & NS \\
\hline Control & 4 & $26.0 \pm 6.6$ & $394 \pm 85$ & $27.6 \pm 2.3$ & $1.6 \pm 4.6$ & $10.2 \pm 17.1$ \\
\hline Arginine, $1 \%$ & & $30.6 \pm 8.7$ & $380 \pm 74$ & $31.6 \pm 3.3$ & $1.0 \pm 6.0$ & $8.5 \pm 17.2$ \\
\hline$P$ & & NS & NS & NS & NS & NS \\
\hline Control & 5 & $46.5 \pm 8.1$ & $363 \pm 80$ & $48.0 \pm 3.6$ & $1.6 \pm 9.4$ & $0.5 \pm 19.8$ \\
\hline Alanine, $2 \%$ & & $52.9 \pm 15.3$ & $325 \pm 59$ & $49.5 \pm 8.8$ & $-3.5 \pm 11.6$ & $-6.7 \pm 20.0$ \\
\hline$P$ & & NS & NS & NS & NS & NS \\
\hline Control & 9 & $20.4 \pm 2.9$ & $252 \pm 23$ & $15.6 \pm 1.2$ & $-4.8 \pm 2.0$ & $-27.5 \pm 10$ \\
\hline D-Histidine, $1 \%$ & & $12.9 \pm 1.8$ & $315 \pm 33$ & $12.6 \pm 0.8$ & $-0.3 \pm 1.4$ & $2.8 \pm 10$ \\
\hline$P$ & & $<0.05$ & $<0.05$ & $<0.05$ & $<0.05$ & $<0.05$ \\
\hline
\end{tabular}

The effect of the addition of $2 \%$ albumin, $1 \%$ glutamine, $1 \%$ arginine, $2 \%$ alanine, and $1 \%$ D-histidine to standard laboratory diet is shown during water diuresis or antidiuresis. Abbreviations are same as those used in Tables I and II.

$\mathrm{PGE}_{2}$. Furthermore, this effect appeared to be a histidine-specific response since isonitrogenous doses of compounds such as albumin, alanine, arginine, and L-glutamine failed to produce similar augmentation. The lack of effect by isonitrogenous supplements further argues against histidine metabolism (such as urea generation) as the basis of its effects. D-Histidine has effects qualitatively similar to those of L-histidine. D-Histidine is not metabolized and therefore its physiochemical properties are probably responsible for its action, similar to our in vitro findings $(9,18)$. The lesser increase of urine osmolality with D-histidine may reflect decreased intestinal absorption of the amino acid, given the stereospecificity of uptake of amino acids in the intestine.
Histidine may influence urinary cAMP and concentration by enhancing the action of vasopressin at the thick ascending limb (TALH) rather than the collecting duct. Two pieces of evidence argue against this thesis. First, an agent which effects $\mathrm{NaCl}$ transport at TALH will increase free-water clearance and the ratio of free-water clearance to volume in the water diuretic animal (such as the Brattleboro rat). This was not the case in rats supplemented with either $1 \%$ or $2.5 \%$ histidine (Table I) even though these groups had the most impressive antidiuretic response. In rats fed higher concentrations of histidine, an increased proximal nephron (decreased volume) sodium and water absorption was noted coupled with a diminished distal nephron sodium absorption (decreased free-water clearance 


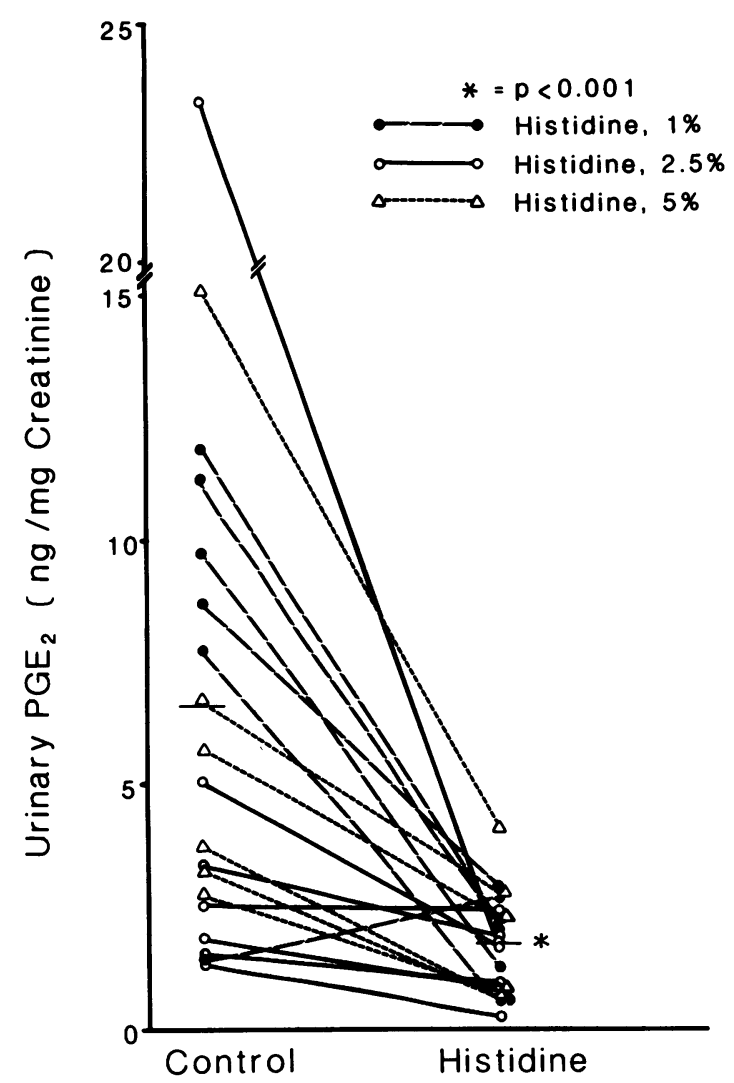

Figure 5. The renal cAMP concentrations of kidneys from Brattleboro rats perfused in vitro in the presence or absence (baseline) of dDAVP $10^{-8} \mathrm{M}$ are shown. The kidneys are from rats fed either regular laboratory diet (control) or laboratory diet enriched with histidine to a final concentration of $5 \%$. This figure demonstrates that dDAVP increases cAMP renal content, and is significantly more effective in the histidine-fed rats.

and decreased ratio of free-water clearance to volume). This argues against histidine's enhancing sodium absorption at TALH. The second, and more direct evidence suggesting an increased response at the level of the collecting duct, is the finding that medullary tonicity was the same in control and rats fed either $1 \%$ or $5 \%$ histidine. This indicates that the increased response to vasopressin cannot be due to an increased rate of absorption by TALH and thus increased medullary tonicity, but rather increased permeability of the collecting duct, allowing for more complete equilibration of luminal fluid with the medulla. However, no definite localization of histidine's action could be inferred from our data.

During baseline periods histidine feeding resulted in a profound decrease of urinary prostaglandins, and presumably prostaglandin production by the kidney. This is similar to the decreased prostaglandin production caused by histidine in tissues such as in fibroblasts and platelets (19), and the toad bladder (18). Furthermore, this may represent a significant mechanism to account for the increased antidiuretic response (18). However, we should be careful in accepting this explanation because our in vivo studies could not identify the specific nephronal site of prostaglandin and cAMP production. In addition, during the most physiologically relevant period of dDAVP stimulation an increased (rather than decreased) $\mathrm{PGE}_{2}$ excretion was noted, directly arguing with such an expla-

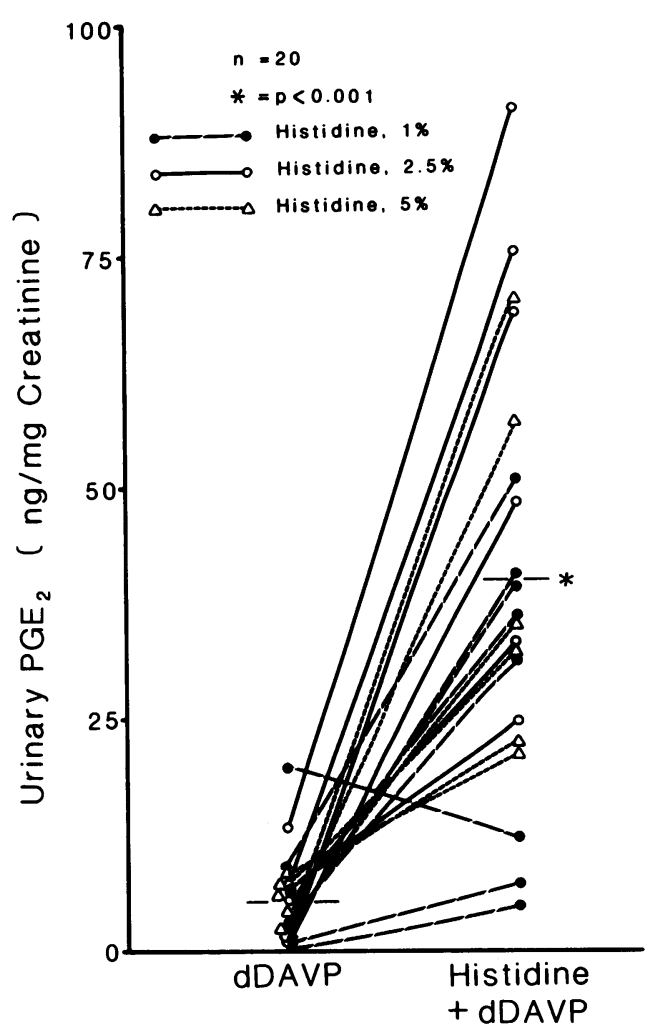

Figure 6. The effect of histidine feeding on $\mathrm{PGE}_{2}$ urinary excretion is shown during baseline periods (water diuresis). A uniform decrease is apparent, independent of the dose of histidine.

nation. Thus, the mechanism at the cell level responsible for the increased response to dDAVP is far from conclusive based on our data. An interesting finding nevertheless is that during histidine feeding, urinary $\mathrm{PGE}_{2}$ increased greatly (to $40 \pm 4.2$ from $1.5 \pm \mu \mathrm{g} / \mathrm{mg}$ creatinine, $P<0.001)$ in response to dDAVP. This phenomenon is difficult to explain since ordinarily dDAVP leads to no increase on urinary $\mathrm{PGE}_{2}$ consistent with a selective $V_{2}$ effect. It is unclear whether in the presence of histidine the binding of dDAVP extends to $V_{1}$ receptors or

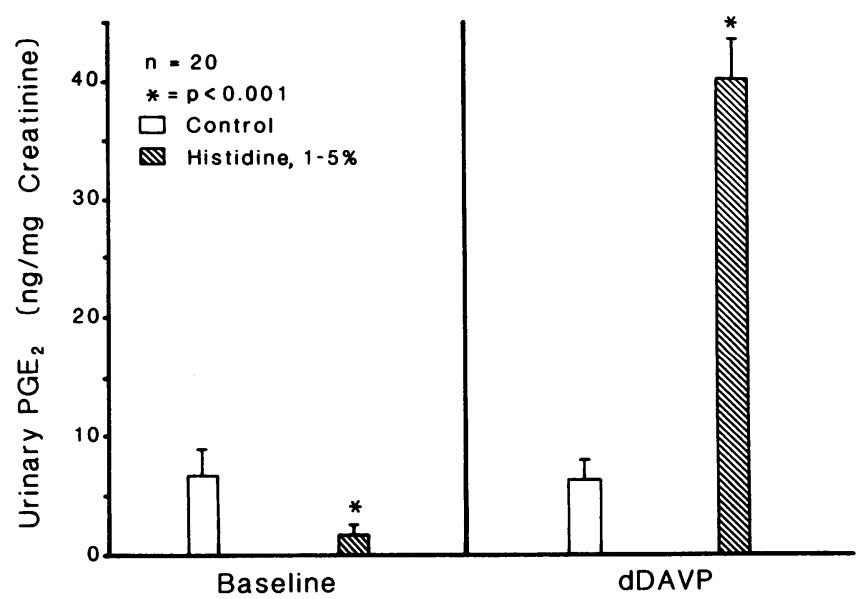

Figure 7. Histidine exaggerates the excretion of prostaglandins in response to dDAVP. The average increase in response to dDAVP in histidine-treated rats is $\sim 1$ order of magnitude. 


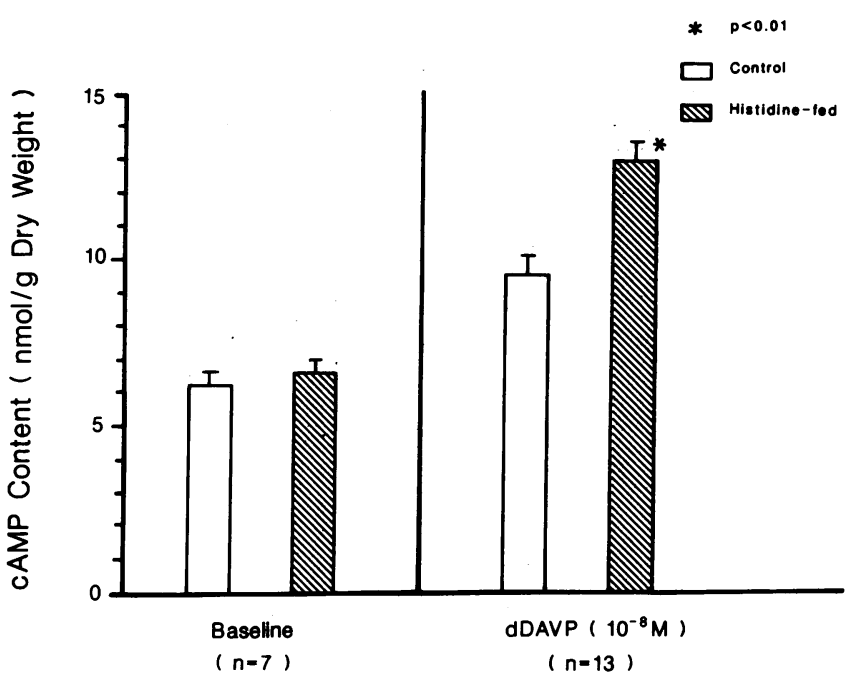

Figure 8. This figure contrasts the adverse effects of histidine intake on urinary prostaglandin $E_{2}$ excretion. As indicated in the text, histidine eliminates baseline urinary $\mathrm{PGE}_{2}$ excretion, while it greatly enhances the urinary $\mathrm{PGE}_{2}$ excretion that follows dDAVP injection.

local biochemical reactions overcome the otherwise inhibitory effects of histidine on $\mathrm{PGE}_{2}$ production.

Our studies did not deal with the metabolism of histidine. Plasma levels of amino acids increase severalfold in the ensuing hours after the ingestion of an amino acid and return back to about control levels within $24 \mathrm{hrs} \mathrm{(10).} \mathrm{Variable} \mathrm{results} \mathrm{have}$ been reported for more prolonged increased histidine intake that may result in a small to moderate increase in plasma concentration in both humans $(20,21)$ and rats $(10)$. We also showed a modest increase in plasma histidine level in the present study. In the rat, liver and brain histidine increase as well (10). It appears logical to postulate that plasma and tissue levels paralleled in some way the amount of histidine intake.

The findings of this study could be helpful in identifying other actions of histidine on the $\mathrm{Na}^{+}$and water reabsorption throughout the nephron. It is known that urine flow, volume, in the diuretic animal (Brattleboro rat) represents a good index of distal delivery of $\mathrm{Na}^{+}$and $\mathrm{H}_{2} \mathrm{O}$. Also, free-water clearance and an even better ratio of free-water clearance to volume is an

Table IV. Tissue Solute Concentrations in Brattleboro Rats

\begin{tabular}{|c|c|c|c|c|c|c|}
\hline & $n$ & $\mathrm{Na}^{+}$ & $\mathrm{K}^{+}$ & $\mathrm{NH}_{4}^{+}$ & Urea & $\begin{array}{c}\text { Total } \\
\text { solutes }\end{array}$ \\
\hline & & & neq/liter & & $m M$ & $m M$ \\
\hline \multicolumn{7}{|l|}{ Cortex } \\
\hline Control & 12 & $52 \pm 3$ & $50 \pm 2$ & $40 \pm 4$ & $12 \pm 1$ & $296 \pm 8$ \\
\hline Histidine, $1 \%$ & 12 & $47 \pm 1$ & $50 \pm 2$ & $43 \pm 3$ & $14 \pm 1$ & $294 \pm 7$ \\
\hline Histidine, $5 \%$ & 11 & $48 \pm 1$ & $49 \pm 2$ & $43 \pm 2$ & $10 \pm 1$ & $290 \pm 6$ \\
\hline \multicolumn{7}{|l|}{ Medulla } \\
\hline Control & 12 & $210 \pm 8$ & $75 \pm 3$ & $21 \pm 4$ & $107 \pm 11$ & $719 \pm 19$ \\
\hline Histidine, $1 \%$ & 12 & $196 \pm 9$ & $85 \pm 3$ & $44 \pm 9$ & $101 \pm 12$ & $751 \pm 20$ \\
\hline Histidine, $5 \%$ & 11 & $204 \pm 16$ & $73 \pm 3$ & $41 \pm 4$ & $95 \pm 6$ & $731 \pm 36$ \\
\hline
\end{tabular}

The concentrations of renal cortical and medullary $\mathrm{Na}^{+}, \mathrm{K}^{+}, \mathrm{NH}_{4}^{+}$ and urea are shown. Tissue tonicity is shown as "total solutes" representing $2\left(\mathrm{Na}^{+}+\mathrm{K}^{+}+\mathrm{NH}_{4}^{+}\right)+$urea. Values are shown as mean \pm SEM.
Table V. Urinary Electrolytes

\begin{tabular}{|c|c|c|c|c|c|}
\hline & $n$ & $\mathbf{U}_{\mathrm{Na}}$ & $\mathrm{U}_{\mathbf{k}}$ & $\mathrm{U}_{\mathrm{Na}} \cdot \mathrm{V}$ & $\mathbf{U}_{\mathbf{K}} \cdot \mathbf{V}$ \\
\hline & & \multicolumn{2}{|c|}{ meq/liter } & \multicolumn{2}{|c|}{ neq/min } \\
\hline \multicolumn{6}{|l|}{ Water diuresis } \\
\hline Control & 6 & $8.3 \pm 1.5$ & $9.5 \pm 1.1$ & $547 \pm 141$ & $585 \pm 84$ \\
\hline Histidine, $1 \%$ & & $4.4 \pm 2.9$ & $8.7 \pm 1.5$ & $351 \pm 164$ & $540 \pm 132$ \\
\hline$P$ & & $<0.05$ & NS & NS & NS \\
\hline Control & 8 & $8.8 \pm 1.5$ & $9.4 \pm 1.3$ & $490 \pm 82$ & $523 \pm 71$ \\
\hline Histidine, $2.5 \%$ & & $4.7 \pm 1.2$ & $8.6 \pm 1.1$ & $261 \pm 81$ & $636 \pm 73$ \\
\hline$P$ & & $<0.05$ & NS & $<0.05$ & NS \\
\hline Control & 12 & $7.8 \pm 0.8$ & $8.5 \pm 0.9$ & $555 \pm 67$ & \\
\hline Histidine, $5 \%$ & & $6.5 \pm 0.9$ & $8.5 \pm 0.7$ & $451 \pm 74$ & $611 \pm 72$ \\
\hline$P$ & & NS & NS & NS & $574 \pm 71$ \\
\hline Control & 26 & $8.2 \pm 0.7$ & $9.0 \pm 0.6$ & $533 \pm 52$ & $578 \pm 45$ \\
\hline Histidine, $1-5 \%$ & & $5.4 \pm 0.9$ & $8.6 \pm 0.8$ & $372 \pm 59$ & $524 \pm 51$ \\
\hline$P$ & & $<0.01$ & NS & $<0.01$ & NS \\
\hline \multicolumn{6}{|l|}{ Antidiuresis } \\
\hline Control & 6 & $5.6 \pm 2.2$ & $6.0 \pm 1.6$ & $70 \pm 18$ & $74 \pm 16$ \\
\hline Histidine, $1 \%$ & & $6.6 \pm 3.2$ & $7.8 \pm 1.6$ & $87 \pm 39$ & $78 \pm 23$ \\
\hline$P$ & & NS & NS & NS & NS \\
\hline Control & 8 & $6.9 \pm 1.9$ & $8.7 \pm 1.9$ & $117 \pm 35$ & $121 \pm 28$ \\
\hline Histidine, $2.5 \%$ & & $6.3 \pm 2.8$ & $9.2 \pm 1.4$ & $83 \pm 29$ & $92 \pm 24$ \\
\hline$P$ & & NS & NS & NS & NS \\
\hline Control & 12 & $9.3 \pm 1.2$ & $8.6 \pm 1.0$ & $132 \pm 31$ & $111 \pm 19$ \\
\hline Histidine, $5 \%$ & & $11.4 \pm 2.2$ & $14.4 \pm 2.7$ & $177 \pm 66$ & $187 \pm 61$ \\
\hline$P$ & & NS & $<0.05$ & NS & NS \\
\hline Control & 26 & $7.9 \pm 1.5$ & $8.1 \pm 0.9$ & $114 \pm 19$ & $106 \pm 13$ \\
\hline Histidine, $1-5 \%$ & & $8.7 \pm 1.6$ & $11.3 \pm 1.5$ & $127 \pm 34$ & $133 \pm 31$ \\
\hline$P$ & & NS & $<0.05$ & NS & NS \\
\hline
\end{tabular}

The effect of variable histidine intake on electrolyte excretion during water diuresis and antidiuresis is shown. Abbreviations: $U_{\mathrm{Na}}$, urinary sodium concentration; $U_{K}$, urinary potassium concentration;

$\mathrm{U}_{\mathrm{Na}} \cdot \mathrm{V}$, urinary $\mathrm{K}^{+}$excretion rate.

index of $\mathrm{Na}^{+}$absorption in the distal nephron (late TALH, distal tubule, and collecting ducts) (22). Feeding histidine $1 \%$ and $2.5 \%$ in addition to the usual rat laboratory diet has no effect on those parameters. The decrease in urinary $\mathrm{Na}^{+}$from $\sim 8.5$ to $4.5 \mathrm{meq} / \mathrm{liter}$, probably indicates a mild increase in distal $\mathrm{Na}^{+}$absorption, small enough not to be apparent by changes in free-water clearance. Higher levels of histidine intake enhanced proximal $\mathrm{Na}^{+}$and water reabsorption (volume) while, if anything, decreased distal $\mathrm{Na}^{+}$absorption (decreased free-water clearance and decreased ratio of free-water clearance to volume). We emphasize that one should be cautious in localizing such effects with clearance studies and that additional techniques (micropuncture, isolated tubular, and so forth) are needed to pursue this issue further.

Our studies have shown in vivo that supplementation with L-histidine enhances the antidiuretic action of dDAVP. These results are analogous to past in vitro toad bladder studies and further suggest that naturally occurring amino acids can act as modulators of the action of antidiuretic hormone. These findings may have important clinical applications. We are currently evaluating the effect of oral histidine on antidiuresis in humans with promising preliminary results.

Furthermore, we have recently found evidence that histi- 
dine influences the renal response to at least one other peptide hormone (23). This is theoretically not surprising since histidine alters the production and function of prostaglandins (18), cAMP, and cytoskeleton (9), all important constituents for the function of peptide hormones in general. Indeed, a more global role for histidine and other amino acids in modulating the action of peptide hormones has been suggested (9). Our present studies therefore could lead to meaningful research to identify the naturally occurring amino acids as modulatory systems in the action of hormones.

\section{Acknowledgments}

The authors thank Drs. I. M. Weiner, L. C. Stoner, R. Giammarco, S. Scheinman, and W. C. Elliott for reading the manuscript and providing helpful advice and suggestions. We thank Terry Robbino and the Word Processing Group for secretarial support. The authors would like to thank Rosemary Fenner for excellent technical support.

This research was supported by Veterans Administration grants (Drs. Carvounis, Moses, and Coulson).

\section{References}

1. Kenjeric, K. 1974. Chemical nature of synaptic transmission to vertebrates. Physiol. Rev. 54:418-540.

2. De Fundis, F. V. 1975. Amino acids as central neurotransmitter. Annu. Rev. Pharmacol. 15:105-130.

3. Shimizu, H., H. L. Ichishitz, and H. Odogizi. 1976. Stimulated formation on cyclic adenosine 3 ',5'-monophosphate by aspartate and glutamate in cerebral cortical slices of guinea pig. J. Biol. Chem. 249:5955-5961.

4. Schmidt, M. H., J. H. Thomberty, and B. B. Malloy. 1977. Effects of kainate and other glutamate analogues on cyclic nucleotide accumulation in slices of rat cerebellum. Brain Res. 121:182-189.

5. Levinsky, N. G., I. Tyson, R. B. Miller, and A. S. Robinson. 1962. The relation between amino acids and potassium in isolated rat muscle. J. Clin. Invest. 41:480-487.

6. Dickerman, H. W., and W. G. Walker. 1964. Effect of cationic amino acid infusion on potassium metabolism in vivo. Am. J. Physiol. 206:403-408.

7. Gilles, R. 1974. Métabolismẹ des acides amines et controle du volume cellulaires. Arch. Int. Physiol. Biochim. 82:423-589.

8. Sundberg, R. J., and R. B. Martin. 1974. Interaction of histidine and other imidazole derivatory with transition metal ions in chemical and biological systems. Chem. Rev. 74:471-517.

9. Carvounis, C. P., G. Carvounis, and B. J. Wilk. 1985. Impor- tance of amino acids on vasopressin-stimulated water flow. J. Clin. Invest. 76:779-788.

10. Harper, A. E., N. J. Benevenga, and R. M. Wohlhueter. 1970. Effects of ingestion of disproportionate amounts of amino acids. Physiol. Rev. 50:428-558.

11. Hewitt, S. 1982. Method for the microassay of endogenous creatinine in blood and urine of small animal rodents. Lab. Anim. 16:201-203.

12. Moses, A. M., R. Fenner, E. T. Schroeder, and R. Coulson. 1982. Further studies on the mechanism by which chlorpropamide alters the action of vasopressin. Endocrinology. 111:2025-2030.

13. Moses, A. M., and R. Coulson. 1980 . Augmentation by chlorpropamide of 1-deamino-8-D-arginine vasopressin-induced antidiuresis and stimulation of renal medullary adenylate cyclase and accumulation of adenosine 3',5'-monophosphate. Endocrinology. 106:967972.

14. Andriole, V. T., and F. H. Epstein. 1965. Prevention of pyelonephritis by water diuresis: evidence for the role of medullary hypertonicity in promoting renal infection. J. Clin. Invest. 44:73-79.

15. Valtin, H. 1966. Sequestration of urea and non-urea solutes in renal tissues of rats with hereditary hypothalamic diabetes insipidus: effect of vasopressin and dehydration on the counter-current mechanism. J, Clin. Invest. 45:337-345.

16. Chaney, A. L., and E. P. Marback. 1962. Modified reagents for determination of urea and ammonia. Clin. Chem. 8:130-138.

17. Epstein, F. H., C. R. Kleeman, S. Puzsel, and A. Hendrikx. The effect of feeding protein and urea on the renal concentrating process. $J$. Clin. Invest. 36:635-641, 1956.

18. Carvounis, C. P., E. T. Schroeder, P. Cushley, P. Hueber, and D. Patchin. 1988. Effects of histidine on vasopressin action: role of decreased prostaglandin production. Am. J. Physiol. 255:F685-F689.

19. Steinhauer, H. B., R. Jackisch, and P. Schollnaeger. 1986. Modification of prostaglandin generation by L-histidine: possible pathogenetic implication in rheumatoid arthritis. Prostaglandins Leukotrienes Med. 13:211-216.

20. Kopple, J. D., and M. E. Swendseid. 1981. Effect of histidine intake on plasma and urine levels, nitrogen balance and $N$-methylhistidine excretion in normal and chronically uremic men. J. Nutr. 111:931-942.

21. Pinals, R. S., E. D. Harris, J. B. Burnett, and D. A. Gerber. 1977. Treatment of rheumatoid arthritis with L-histidine: a randomized placebo-controlled, double-blind trial. J. Rheumatol. 4:414-419.

22. Levinsky, N. G., and M. Levy. 1973. Clearance techniques. In Handb. Physiol. Sect. 8: Renal Physiol. J. Orloff and R. W. Berliner, editors. Williams \& Wilkins Co., Baltimore, MD. 103-118.

23. Carvounis, C. P., R. Coulson, and S. J. Scheinman. 1986. Histidine dissociates the effects of PTH on cAMP production and phosphate excretion. Proc. Am. Soc. Nephrol. 19:186A.(Abstr.) 